\title{
Lope de Andrucha Waddington: una biografía del Fénix para el lienzo de plata $^{1}$ \\ Lope by Andrucha Waddington: a biography of the Fénix for the silver screen
}

\section{Alba Carmona}

Universidad Autónoma de Barcelona

ESPAÑA

alba.carmona@uab.cat

[Hipogrifo, (issn: 2328-1308), 4.2, 2016, pp. 123-134]

Recibido: 26-03-2016/ Aceptado: 28-04-2016

DOI: http://dx.doi.org/10.13035/H.2016.04.02.11

Resumen. Los biopics que trasladan la vida de escritores a la gran pantalla son numerosos, sin embargo, de los dramaturgos canónicos del Siglo de Oro, tan solo la biografía de Lope de Vega ha merecido atención cinematográfica. En el presente artículo se analiza la imagen ofrecida del Fénix en Lope, de Andrucha Waddington (2010), el último biopic del madrileño, en el cual realidad y ficción contribuyen a relatar la experiencia del «primer Lope». Mediante dicho análisis se demuestra que el retrato del vate se fraguó a partir de rasgos que él mismo y otros autores le han atribuido, y cómo la adjudicación de determinadas características, asignadas con harta frecuencia a los protagonistas de este tipo de films, favorecen la disolución de las particularidades de su vida y personalidad.

Palabras clave. Biopic, «primer Lope», dramaturgos del Siglo de Oro, recepción del patrimonio teatral áureo.

Abstract. Biopics of writers abound in cinema; however, of all the canonical Spanish Golden Age authors, only Lope's biography has attracted cinematographic attention. In this paper we analyse the way the Fénix is presented in Lope, by An-

1. Este trabajo se inscribe en el marco de mi investigación predoctoral, realizada gracias a una «Ayuda para contratos predoctorales para la formación de doctores» (BES-2013-064325, MINECO), y se beneficia de mi vinculación a los proyectos «Edición y estudio de treinta y seis comedias de Lope de Vega» (FFI-35950 y FFI2015-66216-P). Agradezco al Dr. Gonzalo Pontón Gijón, director de mi tesis doctoral, la revisión de este trabajo. Todos los errores y limitaciones del trabajo son exclusivamente responsabilidad mía. 
drucha Waddington (2010), the last biopic of the author, in which reality and fiction intertwine to show the life of the «primer Lope». We show that the image of the poet in Waddington's film is drawn from features created both by Lope himself and other authors, and that some of these particular features contribute to dilute the singularities of his life and personality.

Keywords. Biopic, «Primer Lope», Golden Age Playwrights, Reception of the Golden Age Theatre Heritage.

A lo largo de la historia del cine numerosos biopics han trasladado a la gran pantalla la biografía de artistas, varios de ellos escritores. De nuestros dramaturgos canónicos del Siglo de Oro, sin embargo, tan solo se han realizado dos biografías fílmicas, y ambas están dedicadas a la vida de Lope de Vega. No parece gratuita tal coincidencia si tenemos presente la fortuna del Fénix, pues durante el siglo XX y las dos primeras décadas del XXI ha sido el dramaturgo áureo con mayor presencia en las tablas y en el lienzo de plata. Por otra parte, no podemos obviar que el madrileño dejó «un rastro documental mucho más patente que el de ningún otro de nuestros grandes ingenios» ${ }^{2}$. La abundancia de datos que se tienen de su vida habría ofrecido un buen asidero a los responsables de estas dos películas.

La aparición de la primera adaptación cinematográfica de la vida del dramaturgo, La musa y el Fénix (C. I. David, 1935), se enmarca en el contexto de celebración del tricentenario de la muerte del autor. A diferencia de otras manifestaciones conmemorativas realizadas durante la efeméride, documentadas en su momento y posteriormente estudiadas por la crítica académica ${ }^{3}$, poco se puede afirmar con seguridad de esta producción, de la cual no ha quedado copia y cuyas referencias coetáneas son escasas ${ }^{4}$.

El segundo y, por lo pronto, último biopic del dramaturgo se titula Lope, y se trata de una coproducción hispano-brasileña dirigida por Andrucha Waddington, estrenada en España en 2010. Comienza in media res, y aproxima al periodo de la vida del Fénix comprendido entre su regreso de la campaña militar en la Isla Terceira (1583) y su partida al destierro tras el proceso de libelos (1588). Se traslada a la gran pantalla, pues, la historia personal del «primer Lope», un personaje «aventurero, itinerante, insumiso y finalmente fascinado por la corte de los años 80 y 90»5.

Si tenemos en cuenta que el objetivo de la producción era trasladar a la pantalla los años de vida del Fénix anteriores a su consagración como poeta, advertimos que los guionistas no acertaron en el periodo de tiempo escogido para explicar tal etapa de la vida del vate; y es que Lope «ya había conquistado una gran reputación como poeta en 1584 , y también antes» ${ }^{6}$. Pero no es casualidad que la narración fílmica empiece en este momento: con anterioridad a 1583-84 solo se conservan

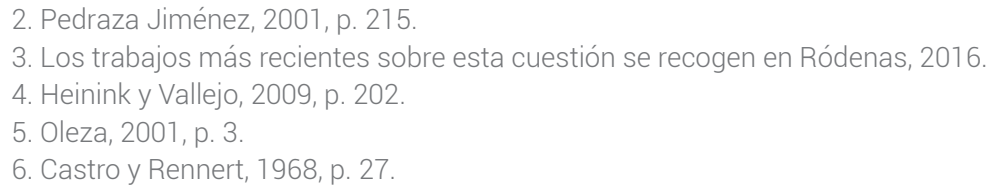


datos sueltos de su biografía, mientras que a partir de esta última fecha la documentación es mucho más abundante? . Parece evidente, por tanto, que en la cinta se narre la experiencia vital del Fénix a partir de los 80 , pues, a pesar de que la recreación de las décadas anteriores habría reflejado mejor los años de formación del dramaturgo, la falta de documentación habría acarreado la multiplicación de licencias dramáticas en detrimento de la veracidad histórica. Por otra parte, el hecho de que en la primera secuencia tan solo se informe de que la acción se desarrolla en Madrid a finales del siglo XVI concede mayor libertad a la hora de organizar cronológicamente los hechos de la vida de Lope, en cuya narración se añaden vicisitudes de las cuales no tenemos noticia ni parece posible que le ocurrieran. Esta fusión de hechos históricos y ficticios, como explicó Waddington, obedece al objetivo de trasladar al público no tanto la biografía del dramaturgo como la leyenda que le envuelve ${ }^{8}$.

La caracterización del Lope fílmico (Alberto Ammann) queda fijada desde los primeros minutos de la cinta, en los cuales se presenta como un acomplejado social con pretensiones nobiliarias. En la primera de las secuencias, escuchamos en over la voz del Fénix, que relata por carta a su madre la victoria de las tropas españolas en las Azores, y le comunica la obtención de un botín, gracias al cual podrán vivir de forma desahogada. La realidad, no obstante, contrasta con la ficción, y aunque la voz en over hace referencia al ánimo henchido y a los bolsillos llenos de los soldados españoles, distintos planos trasladan la imagen de unos hombres que regresan de la guerra en condiciones deplorables. Al llegar a Madrid, Lope pide prestado un caballo y un traje de noble a un amigo que trabaja para el marqués de las Navas. Una vez engalanado, se presenta en el hogar familiar, donde encuentra a su madre a punto de morir. Indiquemos en este punto que si bien es verdad que Lope perteneció a una familia plebeya ${ }^{9}$, el biopic refleja a una familia que roza la indigencia.

Las ansias de ascenso social y pretenciosidad del Fénix se remarcan todavía más en el episodio que sigue, durante el entierro de la madre. Entonces se descubre que el poeta ha hecho fijar en el ataúd un escudo con diecinueve torres; además, ha pagado a unos cómicos para que, vestidos de nobles, finjan ser parientes suyos; para poder costear todos los gastos, Lope ha tenido que pedir prestado de nuevo. Todo ello, provoca la indignación de su hermana (Carla Nieto), que niega que la familia tuviera ninguna vinculación con la nobleza. Parece improbable que Lope llevara a cabo tales extravagancias en el entierro de su madre, la cual murió en 1589, y no tras el regreso de Lope de la expedición militar ${ }^{10}$. No obstante, la secuencia es relevante porque permite evocar el hecho de que Lope en El casamiento en la muerte (1595-1597) inventara un blasón de la familia del Carpio, compuesto también por diecinueve torres, mediante el cual trató de auto-representarse como

7. Castro y Rennert, 1968, pp. 27-28.

8. <http://www.fotogramas.es/Noticias-cine/Alberto-Ammann-Soy-de-los-que-enfrento-con-los-grandes-retos-de-la-vida> [1 1/02/2016].

9. Arellano y Mata, 2011, p. 25.

10. Castro y Rennert, 1968, p. 16. 
noble, y que hizo estampar en varias de sus obras. En este sentido, la reacción de la hermana viene a conectar con las críticas lanzadas contra el Fénix por autores como Cervantes y Góngora ante el pretencioso gesto ${ }^{11}$.

Estas primeras secuencias también sirven para poner de relieve el hecho de que nadie de la familia del Fénix lo respaldara en su sueño de devenir escritor. La ausencia de apoyo familiar se evidencia en la actitud de su hermano mayor (Antonio de la Torre), que intenta convencerle para que acuda junto a él a Lisboa y se aliste en su batallón. Asimismo, su hermana se ríe de él al encontrarlo en el ardor de la composición. No parece, sin embargo, que estas fueran las condiciones en las que el Fénix creciera. A partir del testimonio literario del propio madrileño, se ha indicado que su padre era poeta ${ }^{12}$, la cual cosa, de ser cierta, habría supuesto que se criara en un ambiente, al menos, de respeto por las letras. Además, sus progenitores, al apreciar sus buenas aptitudes para el estudio, decidieron darle una educación ${ }^{13}$. Su paso por la Universidad de Alcalá no puede confirmarse documentalmente, pero el propio poeta hizo referencia a su estancia en las aulas del centro en las dedicatorias de La Arcadia y El desconfiado ${ }^{14}$, y también en la ficción, como en La Dorotea ${ }^{15}$. Asimismo, es harto probable que cursara estudios superiores en la Academia Real Matemática $^{16}$.

Por todo ello, sostenemos que el retrato de la familia mostrado en la cinta participa del esquema de representación empleado habitualmente en el cine para plasmar el ambiente condenatorio que envuelve en particular la vida de los literatos (hayan existido o no). Basta pensar en Total eclipse (A. Holland, 1995), cinta en la cual observamos cómo la familia de Rimbaud se muestra contraria al ejercicio de las letras; en Becoming Jane (J. Jarrold, 2007), donde queda retratada la oposición existente en época georgiana contra el ejercicio de la escritura por parte de la mujer; o en Haganenet (N. Lapid, 2014), en la cual se refleja cómo el padre de un niño de cinco años, Yoav, se niega a fomentar el talento de su hijo. Al igual que en estos casos, en Lope el retrato de la oposición social enfatiza el genio innato del autor, presentado como un ejemplo de superación que se convertirá de acuerdo los títulos de crédito en el escritor «más prolífico de la historia», responsable de «más de 4000 poemas y más de 800 obras teatrales», según rezan las abultadas cifras.

De la película también se desprende que la pasión de Lope por el teatro despierta súbitamente cuando regresa a Madrid ${ }^{17}$. Así, tras asistir a una función de cómicos escribe su primera obra en apenas dos días y se la entrega al autor de

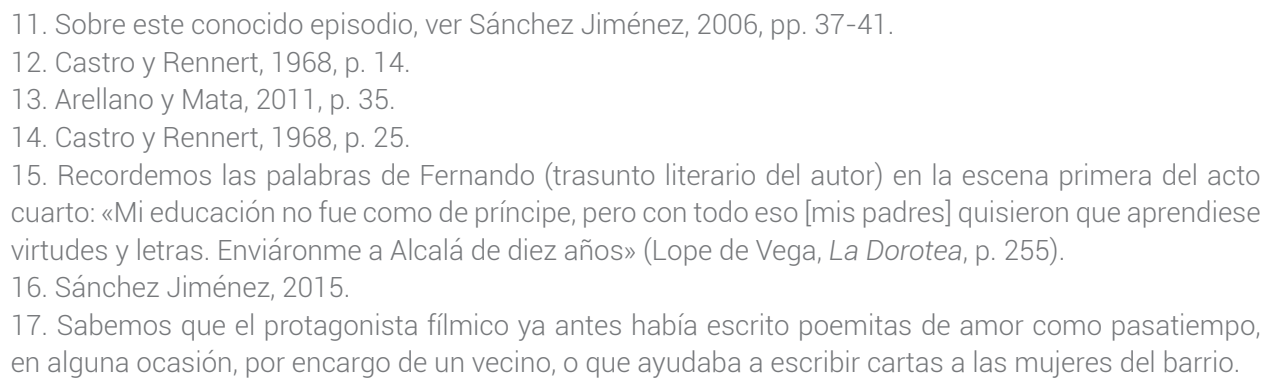


comedias Jerónimo Velázquez (Juan Diego). De acuerdo con el biopic, Velázquez es quien le abre las puertas del mundo teatral: primero, pidiéndole que pase a limpio El cerco de Numancia de Cervantes, y más tarde encargándole cinco comedias. Como vemos, realidad y ficción se superponen también en el relato de los inicios del Fénix como creador, el cual, «no nos ha dejado referencias concretas de sus orígenes como dramaturgo» ${ }^{1}$. Por ello, no debe extrañarnos que los guionistas dieran rienda suelta a su imaginación en el relato de esta cuestión.

A partir de los testimonios de Pérez de Montalbán y del propio Fénix, inferimos que el gusto del madrileño por la escritura y el teatro no habría nacido tan espontáneamente como en el biopic se muestra. Su primer biógrafo apuntó que con tan solo cinco años «era tanta su inclinación a los versos, que, mientras no supo escribir, repartía su almuerzo con los otros mayores por que le escribieran lo que él dictaba» ${ }^{19}$. Asimismo, en su Arte nuevo de hacer comedias (1609), Lope declaraba que escribía comedias «de once y doce años» (v. 219). Es evidente que tales declaraciones deben tomarse con precaución dado su carácter hiperbólico, pero, si tenemos presente el temprano éxito de Lope, son relevantes en la medida en que dan cuenta de su precocidad.

La cinta sí parece ajustarse a la biografía de Lope en lo que tiene que ver con el hecho de que el autor habría iniciado su andadura como dramaturgo tras su regreso de las Azores, y en que sus primeras obras las habría montado la compañía de Velázquez ${ }^{20}$. No obstante, ningún investigador ha valorado que Lope enmendara la obra cervantina, que fue representada en Madrid ${ }^{21}$. A pesar de la falta de correspondencia entre los hechos narrados y los históricos, también este episodio fílmico es útil porque enuncia la rivalidad que marcó la relación entre los autores; además simboliza la incapacidad de Cervantes y otros dramaturgos de su generación para ajustarse a la nueva fórmula dramática lopesca y satisfacer la demandas del público teatral de la época.

A propósito, notemos que el gesto de innovar «may be the most valuated quality sold through biopics, whether it is in vaudeville or microbiology ${ }^{22}, y$, en este sentido son varias las secuencias encaminadas a poner de realce la invención del Fénix de este nuevo modo de escribir comedias. Es relevante, por ejemplo, el fragmento en el que Velázquez reprende al protagonista por haber corregido el texto cervantino, atentado con sus enmiendas contra las normas del teatro. Lope responde sugiriendo que semejantes reglas tan solo encorsetan la imaginación, y añade, haciendo alusión al Arte nuevo de hacer comedias, que, con sus retoques, ha conseguido que la obra del alcalaíno «se parezca más a la vida, que los personajes se parezcan más a nosotros, que sufran y rían [...], [pues] en la vida la risa y el llanto van mezclados».

\footnotetext{
18. García Reidy, 2013, p. 106.

19. Castro y Rennert, 1968, p. 17

20. García Reidy, 2013, p. 106.

21. Cervantes, Ocho Comedias y ocho entremeses nuevos, nunca representados.

22. Custen, 1992, p. 74
} 
La mostración de este tipo de situaciones está desde luego encaminada a acentuar el carácter rupturista de la contribución de Lope en la historia de literatura. Sin embargo, la revolución teatral que propició es presentada con frivolidad, ya que no parece que fuera fruto del esfuerzo. Es cierto que en ocasiones se le muestra trabajando, pero del conjunto de la narración se desprende que los logros del Fénix son más bien resultado del don innato que antes mencionábamos. Vasta remitirse al principio de la película, cuando compone su primera comedia, como advertíamos, en dos días; o cuando, estando en casa del marqués de las Navas (Selton Mello) -noble que le encarga cartas de amor, como lo hacía el histórico duque de Sessa-, improvisa un soneto a medida que lo recita. También es significativo en este sentido que, durante la noche anterior a su intento de embarco en la Armada Invencible, mientras se oculta de sus perseguidores bajo una barcaza, componga lo que él considera la mejor obra que ha escrito hasta entonces ${ }^{23}$.

Notemos en este punto que la caracterización que se nos ofrece de un Lope feraz no corresponde con la invención de los guionistas, sino que conecta con lo imagen preconizada por el propio dramaturgo, otros autores y críticos, coetáneos y posteriores. Recordemos el irónico epíteto que le dedicó Cervantes en el prólogo de sus Ocho comedias: «Monstruo de la naturaleza» ${ }^{24}$. Igualmente, en la secuencia en la que Lope improvisa un soneto en la casa del marqués de las Navas, el retrato del poeta coincide con el esbozado por Góngora en uno de sus sonetos, «A ti, Lope de Vega, el elocuente», en el cual el cordobés insinúa que «repentiza como un vulgar poeta de repente» ${ }^{25}$.

No sabemos con certeza cuánto tiempo dedicaba Lope a componer sus poemas y comedias, pero se ha estimado que entre 1599 y 1610, años de «plenitud artística y vital» ${ }^{26}$, habría escrito una media de diez comedias y media al año; una cifra de producción que queda muy alejada de la sugerida en la película, en la cual, como veíamos, se apunta que escribió su primera comedia en 48 horas. Por otra parte, algunas de las declaraciones realizadas por el madrileño en su correspondencia con el duque de Sessa informan del tiempo y esfuerzo invertido en sus obras teatrales; parece que incluso, en alguna ocasión, el exceso de trabajo provocó que la salud del poeta se resintiera ${ }^{27}$ (quizás exagerara). Tal dedicación, sin embargo, queda difuminada en la cinta, cuyo protagonista, a pesar de escribir a toda prisa y en cualquier lugar, entusiasma al público madrileño con sus poemas de amor y comedias.

23. Puede que se haga referencia a La hermosura de Angélica. El Fénix indicó en el prólogo de la obra que la escribió durante su participación en la Jornada de Inglaterra (Lope de Vega, La hermosura de Angélica, p. 614)

24. «"[M]onstruo" evoca la admiración -la suspensión - que tanto apreciaban los escritores barrocos; sin embargo, también implica falta de armonía, e incluso deformidad» (Sánchez Jiménez, 2006, pp. 8182, n. 3).

25. «Estos personajes tenían la capacidad para improvisar textos sobre cualquier tema que se presentara, demostrando una habilidad que tenía algo de atracción de feria y algo de cualidad cortesana, pues los poderosos podían importunar a los poetas áureos para que compusieran de repente» (Sánchez Jiménez, 2006, pp. 130-131).

26. García Reidy, 2013, pp. 168-175.

27. García Reidy, 2013, p. 205. 
La caracterización propuesta en este sentido contribuye ciertamente a acentuar la admiración que el público puede llegar a sentir por el personaje retratado. Sin embargo, tal representación, a priori positiva, supone un flaco favor para la consideración de la obra lopesca. De hecho, participa de una longeva y persistente genealogía crítica, inaugurada, como decíamos, ya en vida de Lope, y «que había acusado al Fénix de descuidado y de escribir demasiado rápido» ${ }^{28}$. Asimismo, en la construcción de esta faceta del ingenio subyacen connotaciones peyorativas como la improvisación, rudeza y la falta de arte, un conjunto de «defectos» que desde el Seiscientos y hasta la actualidad, se vienen atribuyendo al teatro clásico español y que enturbian su recepción ${ }^{29}$.

Dejando ahora al margen la cuestión de Lope como escritor, digamos que el biopic nos muestra que en los inicios del Fénix como dramaturgo «trabajo y placer fueron a la par» ${ }^{30}$. La película nos permite asistir a uno de los episodios más jugosos de la vida del madrileño: su relación con Elena Osorio (Pilar López de Ayala), hija de Velázquez. Esta, casada, termina por retirar su favor al joven poeta para concedérselo a otro personaje más acomodado, Perrenot (Miguel Ángel Muñoz). Por otro lado, el guión hace coincidir el idilio con el mantenido con Isabel de Urbina (Leonor Watling), a la cual, según las biografías, habría conocido con cierta posterioridad. En efecto, es otro rasgo generalizado en los biopics basados en la vida de literatos el enfatizar la vida amorosa de sus protagonistas ${ }^{31}$ : ello otorga humanidad a los personajes, que podrían resultar distantes si se les presentara excesivamente intelectualizados; y, supone una concesión para la audiencia, bien predispuesta a las historias de amor.

Fijémonos en que la coincidencia cronológica señalada entre la relación amorosa con Urbina y Velázquez, además de establecer en la narración la clásica estructura del triángulo amoroso, contribuye a reforzar el cliché de un Lope mujeriego e inconstante en el amor, también de gran predicamento en vida del autor, e incluso fomentada por él mismo ${ }^{32}$. Tal caracterización alcanza nuestros días, y más allá del biopic es rastreable tanto en la crítica académica como en la cultura popular. Basta con hacer referencia, por ejemplo, al reciente papel de conquistador otorgado al madrileño en los capítulos de «Tiempo de Gloria» y «Tiempo de hidalgos» de El Ministerio del tiempo (2015 y 2016).

Por otro lado, la relación que Lope mantiene con Isabel permite poner de realce la faceta caritativa y piadosa de Lope, pues entra en contacto con ella mientras colabora en un hospital. Notemos que, mediante la ubicación del poeta en tal contexto, la narración fílmica logra nuevamente hacer mención a otros episodios

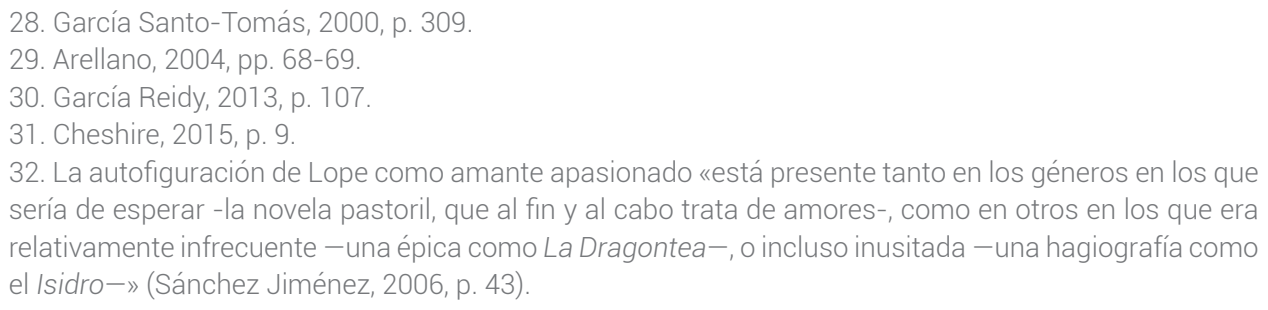


de su vida sin desarrollarlos. Así, establece una continuidad entre la infancia del madrileño, en la cual, según el testimonio de Herrera Maldonado, acostumbraba a acudir junto a su padre y hermanos al Hospital de la Corte, donde atendían a los enfermos ${ }^{33}$. Además, el hecho de que su amigo fray Bernardo (Luis Tosar), que está al cargo de este hospital, plantee a Lope que se dedique a la vida religiosa anuncia su futura ordenación como sacerdote en 1614.

En contraste con esta faceta virtuosa, en el filme se subraya la rebeldía y el carácter delictivo del protagonista a través de la diegetización del proceso de libelos. Tal incidente se inicia con la asistencia de Lope al estreno teatral de su primera obra montada, La conquista del nuevo mundo ${ }^{34}$. Cuando termina la representación, el Fénix descubre un fajo de cuartillas y declama un soneto difamatorio contra Elena y su familia. Entonces, Velázquez ordena hacerle prender. Finalmente, tras provocar un incendio en el teatro durante un duelo, logra escapar, lanzando en su huida múltiples copias de su composición al público. Ya en la siguiente secuencia, vemos cómo Lope rapta a Isabel y huyen a Lisboa. Una vez allí el Fénix decide enrolarse en la Armada Invencible. No obstante, sus planes se ven truncados con la llegada de Perrenot, que lo hace apresar justo antes de embarcar, bajo la acusación de ser «autor de libelo infamante contra la honra y fama de Jerónimo Velázquez y su hija doña Elena Velázquez» y «por ser raptor y estuprador de doña Isabel de Urbina». De vuelta a Madrid, es encarcelado y juzgado.

En el relato de este episodio de la vida de Lope son numerosas las licencias, pero en términos generales se respeta la base histórica de los hechos. Sabemos que Lope sí fue detenido en el Corral de la Cruz la tarde del 29 de diciembre de 1587, pero no es cierto que en aquel momento se estuviera estrenando su primera comedia ni que la representación de esta culminara con la lectura del soneto y el teatro en llamas ${ }^{35}$. El Fénix, antes de ser apresado, tampoco huyó a Lisboa junto a Isabel. Por lo que respecta a la cuestión de la participación del madrileño en la Jornada de Inglaterra, la narración se inclina a favor de la versión de los hechos reflejada en los documentos oficiales de la época, que no dejan constancia de la presencia del

33. Castro y Rennert, 1968, p. 14, n. 4.

34. El nuevo mundo descubierto por Cristobal Colón fue compuesta probablemente años después, entre 1598-1603. No parece gratuita la diegetización de la puesta en escena de esta comedia, cuyo montaje en época de Lope no ha aparecido por el momento documentado. A propósito, cabe mencionar que la lectura escénica que se ofrece en la cinta de uno de los fragmentos reproducidos, en el cual Colón y sus hombres entran en contacto con unas indias vestidas con gamuzas y profusamente infantilizadas en su gestualidad, difiere de la interpretación global que ciertos investigadores han realizado de la obra, en la cual advierten que «el dramaturgo despoja al 'otro' de sus atributos exóticos y acaba construyendo un personaje familiar al público» (Ryjik, 2011, p. 197). La mostración de tales atributos de las nativas estaría destinada a satisfacer el horizonte de expectativas de la audiencia actual, predispuesta y gustosa de advertir los rasgos exotizantes a partir de los cuales se acostumbra a caracterizar al «otro». Por otra parte, notemos que mediante la inclusión de este montaje teatral, y en especial debido a la presencia los Reyes Católicos en este, también se refuerza la imagen estereotipada de un Lope exaltador de los acontecimientos gloriosos de la Monarquía Hispánica.

35. Los guionistas podrían haberse inspirado en el incendio de The Globe en 1613, durante la representación de Henry VIII de Shakespeare. 
madrileño en la batalla naval ${ }^{36}$, a diferencia de lo sugerido por Lope en textos como El bautismo del príncipe de Marruecos ${ }^{37}$, el «Prólogo del autor» de La hermosura de Angélica (1602), o el romance «De pechos sobre una torre» ${ }^{38}$. No obstante, en relación con esta composición, la película parece haber querido reproducir parcialmente el episodio que en ella se dramatiza. De este modo, si bien en el texto Belisa (Isabel de Urbina) se despide amargamente de su amado mientras observa las naves que parten a Inglaterra ${ }^{39}$, en la película también se produce un episodio de fuerte dramatismo, en el cual la joven, desde el puerto suplica a Lope que la lleve con él. Por otro lado, la promesa de Lope de reencontrarse con posterioridad con su mujer también nos remite a las palabras pronunciadas en el romance morisco «Ensílleme el potro rucio» por el moro Azarque a su amada Adalifa en el muelle antes de partir a la guerra (vv. 37-42) ${ }^{40}$.

Según hemos ido detallando, parece evidente que numerosas de las modificaciones descritas respecto a la biografía del Fénix persiguen el objetivo de aproximar su figura a la del poeta maldito, puesta de moda en el Romanticismo, momento a partir del cual han abundado «los autores engrandecidos en razón de sus vicios y comportamientos antisociales, a los que también se les da un halo de santidad negativa $»^{41}$. La adscripción del personaje de Lope a este modelo permite presentarlo de una forma atractiva ante el público contemporáneo, que, al estar poco familiarizado con el dramaturgo, podría mostrar desinterés por su biografía fílmica ${ }^{42}$. No obstante, notemos que en pos de la consecución de este atractivo, detectamos la disolución de la singularidad de la vida del Fénix, la cual, desde esta perspectiva, acaba siendo muy similar a la trayectoria de otros artistas subversivos llevada al celuloide, y entre las cuales podemos mencionar la de Lord Byron en Remando al viento, Rimbaud y Verlain (Total Eclipse), Lautrec (R. Planchon, 1998), el Marqués de Sade (Quills, P. Kaufman, 2000), o El Greco (Y. Smaragdis, 2007).

De todas formas, el carácter delictivo de Lope aparece relativamente amortiguado al final de la película. Así, aunque está documentado que durante el proceso de libelos el poeta defendió su inocencia y que, una vez juzgado, volvió a escribir

\footnotetext{
36. Notemos que en el capítulo mencionado de «Tiempo de Gloria» de El Ministerio del tiempo, aunque en un primer momento el personaje de Amelia (Aura Garrido) apunta que no se sabe con seguridad si Lope se enroló en la Armada, se obvia lo atestiguado por los documentos oficiales y, siguiendo el testimonio del vate, se traslada el embarque de este en el galeón San Juan. De acuerdo con la serie española, en realidad Lope estaba destinado a viajar en el San Esteban, que finalmente naufragó frente a las costas irlandesas; fue precisamente gracias a la intervención de la patrulla del Ministerio que se evitó que el madrileño tomara este buque y salvara la vida.

37. Ver la nota de Pontón en: Lope de Vega, El bautismo del príncipe de Marruecos, p. 947, vv. 2902-2904. 38. Sánchez Jiménez, 2008.

39. Lope de Vega, Rimas humanas y otros versos, pp. 65-66.

40. Blecua anotó que en este romance Lope «parece aludir a su expedición a las Islas Azores, en 1583» (Lope de Vega, Lírica, pp. 70-73).

41. Pedraza, 2001, p. 213.

42. La exaltación de este talante maldito se hipervisibiliza en el título de la versión inglesa de la película: Lope, the Outlaw.
} 
nuevas infamaciones ${ }^{43}$, en la cinta, el protagonista demuestra mayor honestidad al declararse culpable y no reincidir en el delito. Mediante tal enmienda, se nos presenta a un Lope con el cual el espectador empatiza con facilidad, pues comprende que sus maledicencias son fruto del despecho, propio de una naturaleza impulsiva y apasionada. Por el contrario, la fiel reproducción de los acontecimientos históricos en este punto hubiera trasladado la imagen de un Lope poco simpático, premeditadamente revanchista.

\section{CONCLUSIÓN}

A lo largo de este artículo hemos evidenciado que en Lope, para la caracterización del Fénix, se echó mano de rasgos de personalidad adjudicados al madrileño en estudios dedicados a su figura, o bien reflejados en textos del propio poeta y otros autores, tanto de su época como posteriores. Asimismo, hemos comprobado que en el esbozo de este retrato también se reciclaron lugares comunes típicos en el cine y especialmente en el género del biopic; un reciclaje mediante el cual, a pesar de alejarse de la vida del vate, se pretendió garantizar la rentabilidad de la cinta.

Cabe preguntarse, para terminar, si merecía la pena adulterar la biografía de Lope para hacerla más comercial. Como ya advirtió el propio Ammann ${ }^{44}$, los textos y estudios que dan cuenta de la vida del Fénix refieren un conjunto de acontecimientos vitales que darían para una cuarentena de películas, con lo cual la rentabilidad estaría asegurada. No obstante, también es verdad que buena parte de esta literatura, especialmente la publicada con inmediata posterioridad a los trabajos de Maravall y Díez Borque en los 70, trasladan la imagen de un autor reaccionario, «dispuesto a prostituir su pluma a los intereses y clases dominantes del absolutismo inmovilista» ${ }^{45}$.

Lope, como advertíamos, también esboza la imagen de un joven con ansias de medro, que compone obras de teatro en las cuales dramatiza los acontecimientos históricos de su patria, y que escribe las cartas de amor de un noble. Pero, a lo largo de la cinta, el acento se pone en su faceta más humana, por lo que, de resultas, en la retina del espectador, queda grabada la imagen de un Lope postideológico, básicamente regido por los designios del amor, es decir, mucho más amable y afín a la sensibilidad contemporánea que el personaje tradicionalmente reflejado en los libros.

\section{BIBLIOGRAFÍA}

Arellano, Ignacio, «Algunos problemas y prejuicios en la recepción del teatro clásico español», en Proyección y significado del teatro clásico español, coord. José

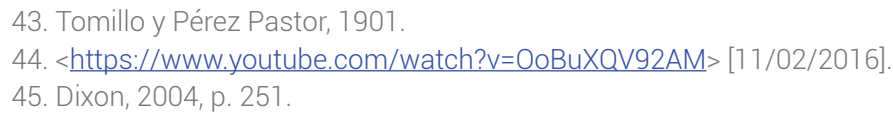


María Díez Borque y José Alcalá-Zamora, Madrid, Sociedad estatal para la acción cultural exterior, 2004, pp. 53-78.

Arellano, Ignacio y Carlos Mata, Vida y obra de Lope de Vega, Madrid, Homo Legens, 2011.

Castro, Américo y Hugo A. Rennert, Vida de Lope de Vega: 1562-1635, Salamanca, Anaya, 1968.

Cervantes, Miguel de, Ocho comedias y ocho entremeses nuevos, nunca representados (ed. facsímil), Madrid, Real Academia Española/Castalia, 1984.

Cheshire, Ellen, Bio-Pics: A Life in Pictures, New York, Columbia University Press, 2015.

Custen, George F., Bio/pics: How Hollywood Constructed Public History, New Brunswick, Rutgers University Press, 1992.

Dixon, Victor, «La auténtica trascendencia del teatro de Lope de Vega», en Proyección y significado del teatro clásico español, coord. José María Díez Borque y José Alcalá-Zamora, Madrid, Sociedad estatal para la acción cultural exterior, 2004, pp. 247-256.

García Reidy, Alejandro, Las musas rameras: oficio dramático y conciencia profesional en Lope de Vega, Madrid/Frankfurt, Iberoamericana/Vervuert, 2013.

García Santo-Tomás, Enrique, La creación del Fénix: recepción crítica y formación canónica del teatro de Lope de Vega, Madrid, Gredos, 2000.

Heinink, Juan B. y Alfonso C. Vallejo, Catálogo del cine español: films de ficción 1937-1940, Madrid, Filmoteca española, 2009.

Oleza, Joan, «El primer Lope: Un haz de diferencias», Ínsula: Revista de letras y ciencias humanas, 2001, pp. 12-14. Versión en línea: http://www.uv.es/entresiglos/oleza/pdfs/hazdedife.pdf [25/05/2016].

Pedraza Jiménez, Felipe B., «Imágenes sucesivas de Lope», en En torno al teatro del Siglo de Oro: XV Jornadas de Teatro del Siglo de Oro, coord. Irene Pardo Molina y Antonio Serrano Agulló, Almería, Instituto de estudios almerienses, 2001, pp. 211-232.

Ródenas, Domingo (ed.), Lope de Vega y la Edad de Plata, Anuario Lope de Vega: texto, literatura, cultura, 22, 2016.

Ryjik, Veronika, Lope de Vega en la invención de España: el drama histórico y la formación de la conciencia nacional, Woodbridge, Tamesis, 2011.

Sánchez Jiménez, Antonio, Lope pintado por sí mismo: mito e imagen del autor en la poesía de Lope de Vega Carpio, Woodbridge, Tamesis, 2006.

Sánchez Jiménez, Antonio, «Lope de Vega y la Armada Invencible de 1588: biografía y poses del autor», Anuario Lope de Vega, 14, 2008, pp. 239-260 
Sánchez Jiménez, Antonio, «Lope y la Academia Real Matemática», en Wort und Zahl/Palabra y número, ed. Christoph Strosetzki, Heidelberg, Universitätsverlag Winter, 2015, pp. 149-169.

Tomillo, Atanasio y Cristóbal Pérez Pastor, Proceso de Lope de Vega: por libelos contra unos cómicos, Madrid, Fortanet, 1901.

Vega, Lope de, Arte nuevo de hacer comedias, ed. Enrique García Santo-Tomás, Madrid, Cátedra, 2009.

Vega, Lope de, El bautismo del Príncipe de Marruecos, en Comedias. Parte XI (Tomo II), ed. Gonzalo Pontón, Barcelona, Gredos, 2012, pp. 793-960.

Vega, Lope de, La Dorotea, ed. Donald McGrady, Barcelona, Círculo de Lectores/ Real Academia Española, 2011.

Vega, Lope de, La hermosura de Angélica, en Lope de Vega, Poesía, I. La Dragontea. Isidro. Fiestas de Denia. La hermosura de Angélica, ed. Antonio Carreño, Madrid, Biblioteca Castro, 2002, pp. 609-970.

Vega, Lope de, Lírica, ed. José Manuel Blecua, Madrid, Castalia, 1981.

Vega, Lope de, Rimas humanas y otros versos, ed. Antonio Carreño, Crítica, BarceIona, 1998. 